\title{
Improving Thin Strip Profile Using Work Roll Cross and Work Roll Shifting Methods in Cold Strip Rolling
}

\author{
Hasan Tibar and Zhengyi Jiang \\ School of Mechanical, Materials and Mechatronic Engineering, University of Wollongong, \\ Wollongong, NSW 2522, Australia
}

Correspondence should be addressed to Zhengyi Jiang; jiang@uow.edu.au

Received 14 September 2016; Accepted 13 November 2016; Published 9 January 2017

Academic Editor: Manoj Gupta

Copyright (C) 2017 H. Tibar and Z. Jiang. This is an open access article distributed under the Creative Commons Attribution License, which permits unrestricted use, distribution, and reproduction in any medium, provided the original work is properly cited.

\begin{abstract}
The optimization of rolling parameters in order to achieve better strip shape and to reduce rolling force is a challenge in rolling practice. In this paper, thin strip asymmetrical rolling of aluminum at various speed ratios under lubricated condition has been investigated at various combinations of work rolls cross (WRC) angles and work rolls shifting (WRS) values. The effects of strip width, reduction, and rolling speed on strip shape taking WRC and WRS into consideration are discussed. Results show that strip profile improves significantly when the WRC angle is increased from $0^{\circ}$ to $1^{\circ}$, with an associated reduction in rolling force. Increasing WRS value from 0 to $8 \mathrm{~mm}$ improves the strip profile as well but not as significantly as when WRC angle is increased. No significant improvement was found in strip shape when the strip width was increased. At higher reduction, the strip shape was improved; a decrease in the rolling force was also observed. A higher speed ratio was found to be effective only at a higher WRC angle. The effect of lubrication on the strip profile was significant. Results indicate that an optimum combination of WRC, WRS, reduction, width, and speed ratio under lubricated conditions can ensure an improved exit strip profile, reduce rolling force, and obtain a better quality strip.
\end{abstract}

\section{Introduction}

Cold rolled thin metallic strips have wide applications in the electronics and instrument industries $[1,2]$. These industries require exceptional accuracy of the strip, as the devices that utilise the cold rolled thin strip are required to have an accurate and precise profile and flatness. In these devices, the strip is used as an electrical contact and a signal receiver. In industry, the variety of cold rolled thin strip applications with gauges of less than $0.5 \mathrm{~mm}$ thick has increased, and the demand for high quality of thin strips has compelled the industry to attain higher performance standards in order to remain competitive [3]. For instance, by reducing material thickness from $0.2 \mathrm{~mm}$ to $0.1 \mathrm{~mm}$, both the cost and the component weight can be significantly reduced. Producing thinner strips, however, requires more money and time $[4,5]$. On the other hand, because of the elastic deformation of the rolls during the rolling process, maintaining thin strip shape and profile and dimensional accuracy is difficult [6].
In order to sustain the market competitiveness of strip rolling, there is a strong focus on improving the manufacturing quality and productivity [3]. Two of the most critical characteristics which have a great influence on both the rolling process and quality of the product are the shape and profile of the thin strip [7]. The quality of the strip is mainly governed by the optimization of the rolling parameters, such as the rolling speed, reduction, strip width, friction, roll pair cross angle, and work roll shifting value. Thus, if the rolling parameters are imperfectly specified, the loading force causes elastic deflections of the rolls $[8,9]$ which has an effect on the shape and profile of the rolled strip and thus its quality.

A variety of advanced control shape rolling mills $[10,11]$ have been designed. The strip profile can be controlled by varying the shape of the gap between the work rolls by using advanced rolling mills [10]. Such roll gap profile control can be carried out on mills equipped with work roll crossing and by making use of a combination of roll axial shifting and asymmetrical rolling. 

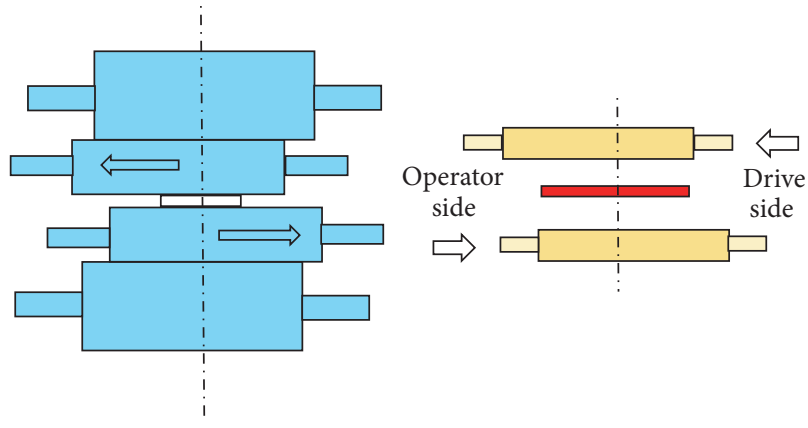

(a)
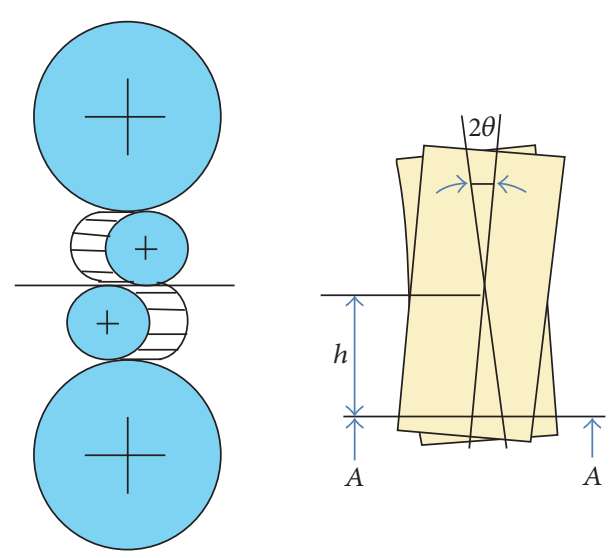

(b)

FIGURE 1: (a) Work rolls shifting system. (b) Work roll crossing system.

In work roll shifting method, the aim is to make the strip thickness uniform and improve the flatness over a wide range of strip widths by shifting rolls of special shapes. Currently, work roll shifting mill is the most effective mill for strip shape control $[12,13]$ because it improves the strip crown accuracy and edge phenomenon, as well as permitting schedule free rolling $[14,15]$ by changing the gap equivalent profile in the roll bite $[10,16]$. Work roll shifting in the axial direction can be achieved by the cyclic shift method (CS) as shown in Figure 1(a). The application of axial side shifting of the work rolls using the cyclic shift method has been shown to evenly distribute the roll wear until a smooth roll crown can be obtained [17].

The purpose of work roll crossing is to obtain a larger efficiency of shape and profile control by increasing the roll gap by increasing the distance from the roll center [18]. By slightly crossing the upper and lower work rolls and reducing the roll force across the roll from the center to the edge of the strip, a bigger crown can also be achieved. It is very similar to crown control function. This can be seen in Figure 1(b).

Asymmetrical rolling is where the rolling velocities, of the work rolls, are different $[19,20]$. As shown in Figure 2(a), the work rolls have unequal diameters and therefore unequal velocities. There are several ways through which asymmetrical rolling can be achieved. One is by having equal diameters of the work rolls and rotating them at different angular speeds and the other is to have different diameters of work rolls and operate them at equal angular speeds. In addition, in general, asymmetrical rolling occurs when diameters as well as the angular speed of the two rolls vary at the same time.

Cross shear region is often generated between the backward and forward slip zones during the asymmetrical rolling process (Figure 2(b)) [21]. A study by Pan and Sansome [22] has shown that asymmetrical rolling can decrease the rolling force and torque by up to $40 \%$. It has also been shown that there is a significant reduction in the rolling pressure [19] and that it is an effective method for large thickness reduction [19].
In this study, asymmetrical cold rolling of thin aluminum strip under lubricated condition is investigated at various speed ratios. The effect of various parameters such as the work rolls cross angle, work roll shifting values, rolling speed, and reduction on the strip shape, profile, and rolling force are discussed.

\section{Rolling Mill and Experimental Procedures}

Cold rolling of aluminum strip $(0.5 \mathrm{~mm} \times 400 \mathrm{~mm})$ was carried out at a roll speed ratio of 1.3 under lubricated conditions using a 4-high Hille 100 rolling mill. The rolling setup involved upper and lower work rolls $(63 \mathrm{~mm}$ and $83 \mathrm{~mm}$ dia, $250 \mathrm{~mm}$ length), respectively, and backup roll $(228 \mathrm{~mm}$ dia, $250 \mathrm{~mm}$ length). The work rolls and backup rolls specifications are recorded in Table 1 . Rolling torque was $0-13 \mathrm{kNm}$ and rolling force was $0-1500 \mathrm{kN}$. The strip width selected for this study is $80 \mathrm{~mm}$ and $100 \mathrm{~mm}$. The rolling force and torque were measured by a load cell mounted on the backup roll and a sensor cell connected to the gearbox and backup roll, respectively. Various WRC angles and WRS values were obtained by adjusting the roll nick using screw shafts in the upper and lower side blocks to axially slide the upper and lower work roll towards the operator and drive sides, respectively. As shown in Figures 3(a) and 3(b), work roll cross angles of $0^{\circ}, 0.5^{\circ}$, and $1.0^{\circ}$ and work roll shifting values of $0,4.0$, and $8.0 \mathrm{~mm}$ were selected, respectively. A roll speed ratio of 1.3 was selected at 20 and $30 \mathrm{rpm}$ roll speeds under lubricated condition.

\section{Experimental Results and Discussion}

This section presents the results obtained from cold rolling of thin aluminum strip at a speed ratio of 1.3 under lubricated conditions. The effect of various rolling parameters that include WRC angles, WRS values, rolling speed, strip width, and reduction ratio are discussed in detail. Additionally, the effect of multiple passes on strip shape and profile has also been investigated. 


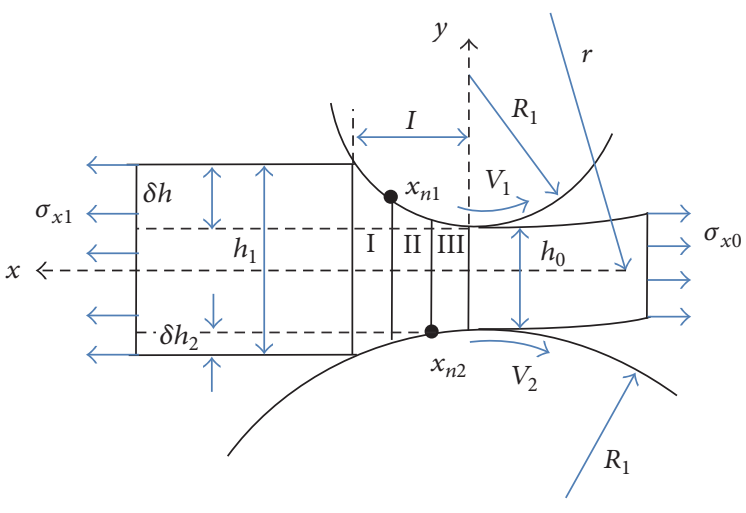

(a)

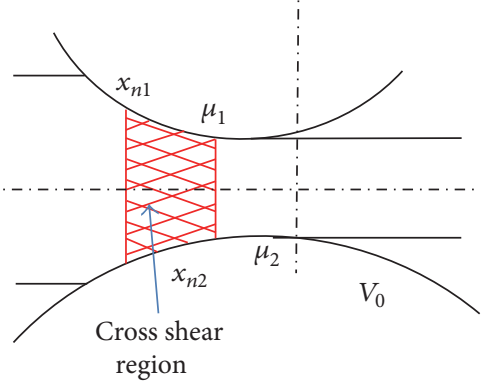

(b)

FIgURE 2: (a) Asymmetrical rolling and (b) cross shear region in asymmetrical rolling process.

TABLE 1: Work roll and backup roll specifications.

\begin{tabular}{|c|c|}
\hline \multicolumn{2}{|c|}{ Material of work roll and backup roll } \\
\hline Grade & $\mathrm{CDH} 25$ \\
\hline $\mathrm{C}$ & 0.90 \\
\hline Sil & 0.55 \\
\hline $\mathrm{Mn}$ & 0.45 \\
\hline $\mathrm{P}$ & 0.012 \\
\hline$S$ & 0.003 \\
\hline $\mathrm{Ni}$ & 0.15 \\
\hline $\mathrm{Cr}$ & 3.19 \\
\hline Mo & 0.26 \\
\hline $\mathrm{Cu}$ & 0.25 \\
\hline $\mathrm{V}$ & 0.009 \\
\hline \multicolumn{2}{|c|}{$\begin{array}{l}\text { Induction hardening, cryogenic treatment, and } \\
\text { surface condition }\end{array}$} \\
\hline Hardness & HRC 65 \\
\hline Depth of heat treatment layer & $\begin{array}{c}>1.0 \mathrm{~mm} \text {, heat treatment is } \\
\text { conducted after roll groove } \\
\text { is machined }\end{array}$ \\
\hline $\begin{array}{l}\text { Work roll and backup roll } \\
\text { surface roughness }\end{array}$ & $0.2 \mu \mathrm{m}$ \\
\hline
\end{tabular}

3.1. Improving Strip Profile through Work Roll Cross Angle and Work Roll Shifting. Figure 4(a) shows the effect of work roll cross angle on the exit strip profile under the parameters of no work roll shifting, $30 \%$ reduction, $20 \mathrm{rpm}$ rolling speed, and $80 \mathrm{~mm}$ strip width at 1.3 speed ratio under lubricated conditions. At zero work roll cross angle, the strip profile tends to decrease significantly towards the edges resulting in strip crown. Near the strip edges, there was minimum resistance to the transverse flow of the rolled material, which is often a characteristic of strips produced using conventional rolling. However, when the work roll cross angle was changed from 0 to $0.5^{\circ}$, the exit strip profile tended to become flat. The flatness further increased when the work rolls cross angle increased to $1^{\circ}$. This indicates that, increasing the work rolls cross angle, uniformity of roll gap distribution can be maintained, and, therefore, this leads to a larger efficiency of the shape and profile control. In order to illustrate this more clearly, the metric of crown and edge can be used to estimate the strip profile. The strip crown C5 is defined as the variation value between the thickness at the strip center and thickness at a $5 \mathrm{~mm}$ distance from the edge, and the edge drop Ce is defined as the variation value between the thickness at the $35 \mathrm{~mm}$ distance from the edge and the thickness at $10 \mathrm{~mm}$ distance from the strip edge. Figure 4(b) shows the effect of work roll cross angle on C5 and Ce. Both C5 and Ce decreased when the WRC angle was increased. This is attributed to the fact that, by controlling the crossing angle, the transverse flow of the material can be controlled.

Figure 5(a) shows the effect of work roll shifting on strip profile without work roll cross angle, $30 \%$ reduction, $20 \mathrm{rpm}$ rolling speed, and $80 \mathrm{~mm}$ strip width at 1.3 speed ratio under lubrication conditions. It is obvious that the work roll shifting is not significant in reducing the strip profile compared to work rolls cross angle effect; however, with an increase of work roll shifting value, the strip profile becomes better. The rolling pressure distribution becomes more uniform due to the relative shifting between the upper and lower rolls. The strip crown and edge drop also decreased with increasing roll shifting values, as shown in Figure 5(b).

It is obvious that the work rolls cross angle and work roll shifting affect the strip profile independently and the combined effect of work rolls cross angle and work roll shifting is of high interest. Figure 6(a) shows the combined effect of these parameters. The strip profile was reduced significantly as the work rolls cross angle increased combining with a higher roll shifting value. In this case, the higher roll shifting value combined with higher rolls cross angle ensured minimum resistance to the transverse flow of material, while uniformly distributing the pressure on the strip, resulting in a significant reduction of strip profile.

Figure 6(b) shows the effect of work roll cross angle and work roll shifting on rolling force. As can be seen, when the work rolls cross angle is not introduced, roll shifting requires a higher rolling force, and this decreases with an increase of 


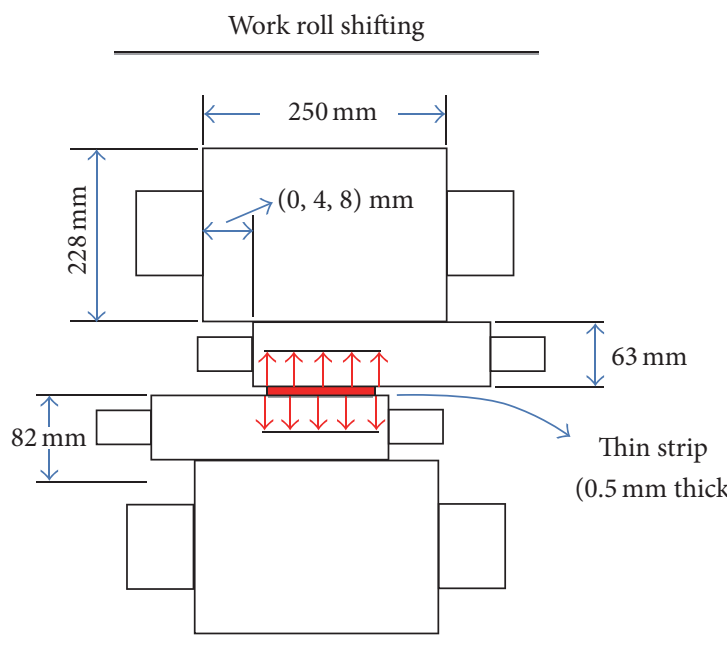

(a)
Work roll crossing

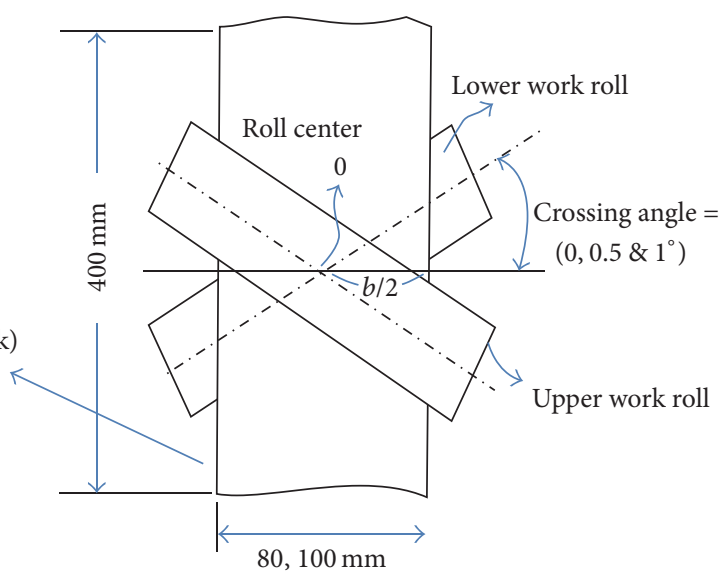

(b)

Figure 3: The schematic of (a) work roll shifting and (b) work roll crossing.

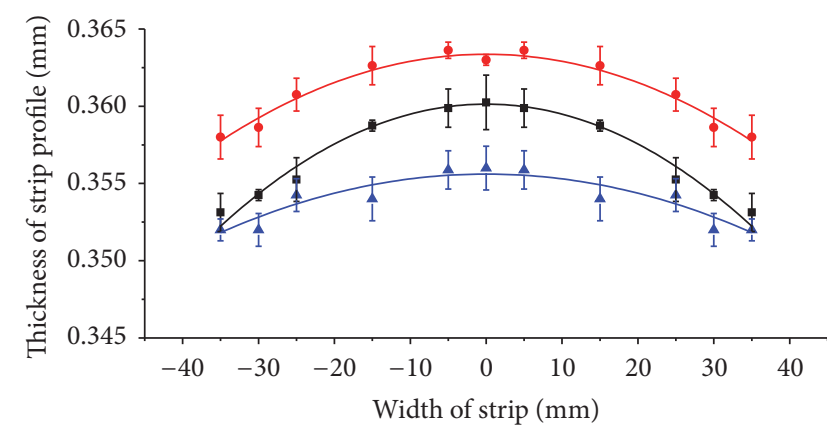

- = "0 WRC, 1st Pass"

- = "0.5 WRC, 1 st Pass"

$\Delta=$ "1 $1^{\circ}$ WRC, 1 st Pass"

(a)

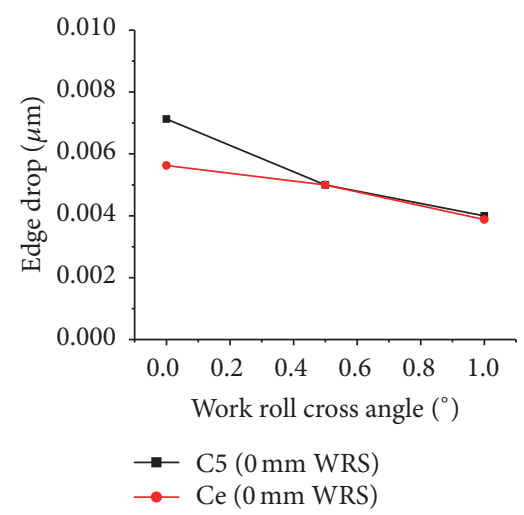

(b)

FIGURE 4: (a) Effect of WRC angle on strip profile. (b) Effect of WRC angle on the strip crown and edge drop.

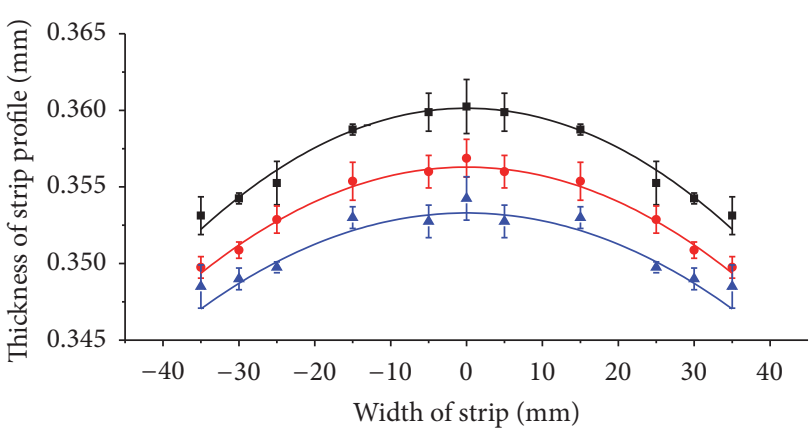

- = "no WRS, 1st Pass"

- = "4 mm WRS, 1st Pass"

॥ = "8 mm WRS, 1st Pass"

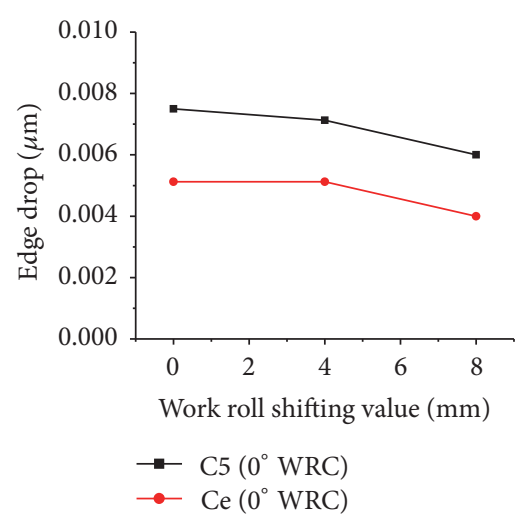

(b)

FIGURE 5: (a) Effect of work roll shifting on strip profile. (b) Effect of work roll shifting value on strip crown and edge drop. 


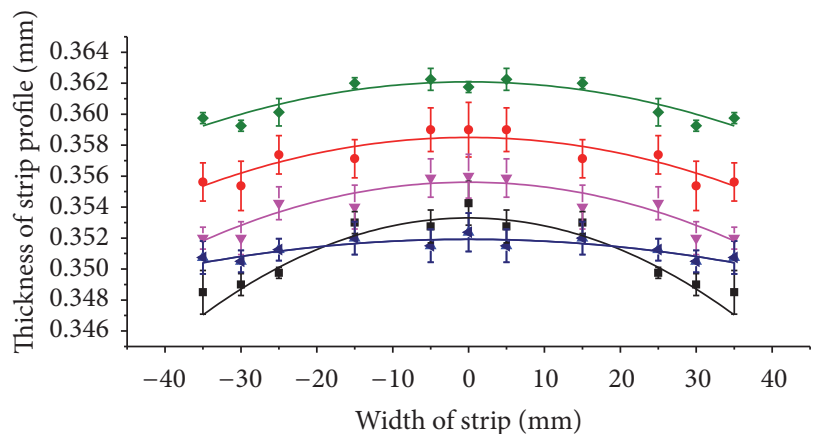

- 1.3- $0^{\circ}$ WRC and $8 \mathrm{~mm}$ WRS

- 1.3-0.5 WRC and $8 \mathrm{~mm}$ WRS

- $1.3-1^{\circ}$ WRC and $8 \mathrm{~mm}$ WRS

(a) $\checkmark$ 1.3- $1^{\circ}$ WRC and no WRS

- 1.3-1 $1^{\circ}$ WRC and $4 \mathrm{~mm}$ WRS

- 1.3-1 $1^{\circ}$ WRC and $8 \mathrm{~mm}$ WRS

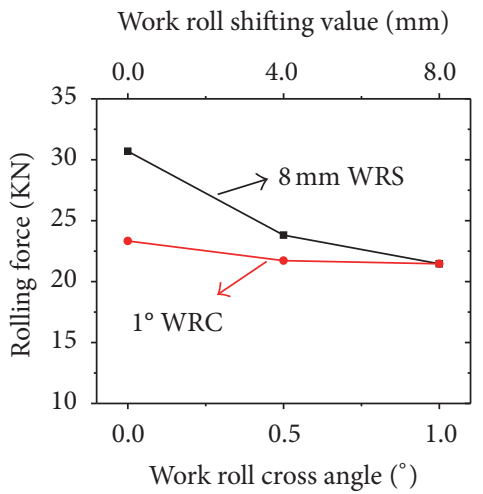

(b)

FIGURE 6: Combined effect of work roll cross angle and work roll shifting on (a) strip profile and (b) rolling force.

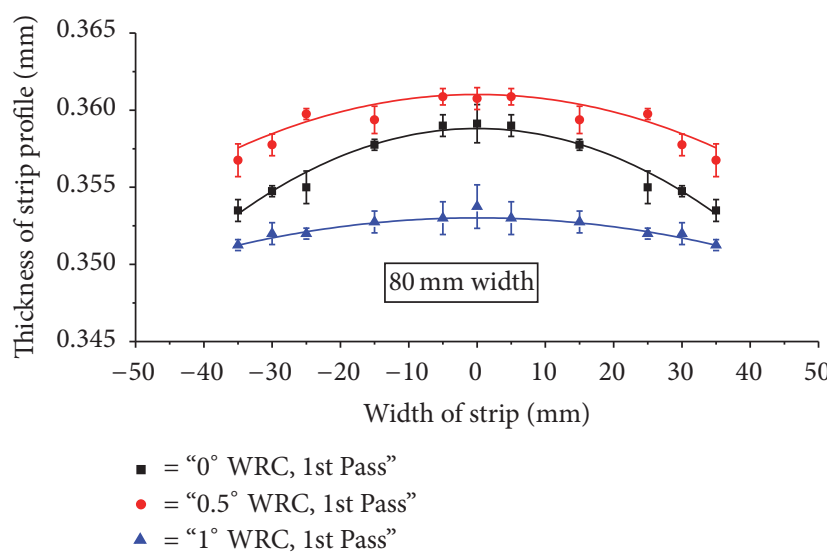

(a)

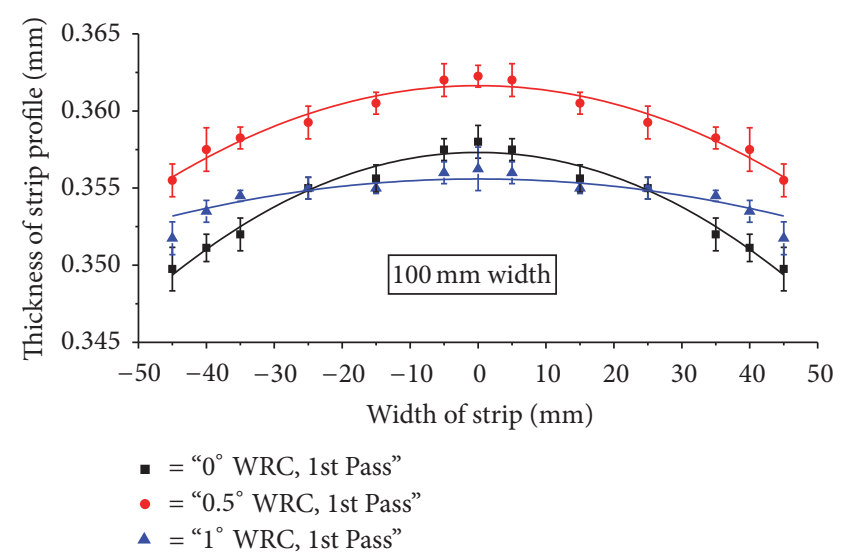

(b)

FIGURE 7: Effect of width on strip profile at various rolls cross angles for (a) $80 \mathrm{~mm}$ width strip and (b) $100 \mathrm{~mm}$ width strip.

rolls cross angle. This indicates that work rolls cross angle has a significant effect on rolling force compared to that the of roll shifting.

3.2. Improving the Strip Profile through Strip Width. Figures 7 (a) and 7(b) show the effect of strip width on strip profile for 80 and $100 \mathrm{~mm}$, respectively, with $4 \mathrm{~mm}$ work roll shifting at $30 \%$ reduction and $20 \mathrm{rpm}$ speed at 1.3 speed ratio under lubrication conditions. As can be seen, with $4 \mathrm{~mm}$ work roll shifting and for the same width, the strip profile becomes better with an increase in work rolls cross angle. The strip profile tends to be better for small width strip. An increased width causes nonuniform roll gap distribution leading to strip crown. As the width decreases $(80 \mathrm{~mm})$, the material is distributed more evenly with the roll gap making the strip profile better. Figure 8 shows the effect of strip width on rolling force at various work rolls cross angles. The rolling force was found to be higher for larger width $(100 \mathrm{~mm})$. This is attributed to the larger rolling force required to plastically deform the larger volume of the material with a large width strip. For the same width, the rolling force significantly dropped with an increase in work rolls cross angle. This is attributed to the uniform roll gap distribution achieved by work rolls cross angle, which allows minimum resistance to the transverse flow of the metal, therefore reducing the force on the rolls.

3.3. Improving the Strip Profile through Reduction Ratio. The effects of reduction (20 and 30\%) on strip profile at various work rolls cross angles and a work roll shifting of $4 \mathrm{~mm}$ for $20 \mathrm{rpm}$ speed, $80 \mathrm{~mm}$ strip width, and 1.3 speed ratio under lubricated conditions are shown in Figures 9(a) and 9(b), respectively. It is clear that, with increased reduction, the strip profile becomes better. This is accomplished through higher rolling force which is required for the increased reduction, which provides a better flow of material within the roll gap, and a uniform distribution is enhanced. Moreover, for a specific reduction ratio, the strip profile is improved with an increase of work rolls cross angle which tends to maintain the uniformity of roll gap. 


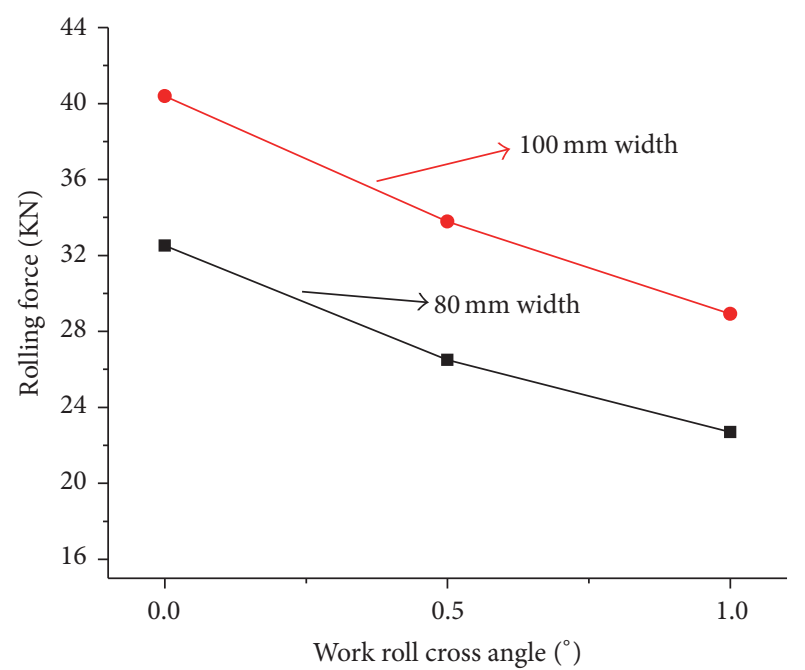

FIGURE 8: Effect of width on rolling force.

3.4. Improving the Strip Profile through Rolling Speed. Figures 10 (a) and 10(b) show the effects of rolling speed (20 and $30 \mathrm{rpm}$ ), respectively, on strip profile at various work rolls cross angles and a fixed roll shifting value of $4 \mathrm{~mm}$ using $30 \%$ reduction, $80 \mathrm{~mm}$ strip width, and 1.3 speed ratio under lubricated conditions. The exit strip profiles indicate that the effect of work rolls cross angle is similar for both 20 and $30 \mathrm{rpm}$ (an improvement in strip profile). However, the resulting strip thickness is lower in the case of a higher rolling speed. This indicates that an optimum combination of rolling speed and work rolls cross angle yields a better strip profile as well as reduced thickness. The effect of rolling speed on rolling force is shown in Figure 11. It can be seen that there is no significant change of rolling force for different rolling speeds, as the net contact surface is essentially the same in both cases, thus requiring a similar rolling force.

3.5. Strip Shape Control. Figure 12 shows the rolled strip at various work rolls cross angles for $80 \mathrm{~mm}$ and $100 \mathrm{~mm}$ strip width at speed ratio of 1.3 , no work roll shifting, $30 \mathrm{rpm}$ rolling speed, and $20 \%$ reduction under lubricated conditions. As can be seen, at $0^{\circ}$ work rolls cross angle, no significant change of strip shape is observed. However, at $0.5^{\circ}$ WRC angle, the strip profile improved in terms of flatness in both cases of $80 \mathrm{~mm}$ and $100 \mathrm{~mm}$ width. At $1^{\circ} \mathrm{WRC}$ angle, a superior flatness is observed in $80 \mathrm{~mm}$ width strip. However, in case of $100 \mathrm{~mm}$ width strip, though the flatness improved, a curvy shape strip is reported which is known as center buckle. The center buckle appeared because of the absence of tension and the higher reduction at the center than the edge of the strip. As there was no tension acting on the two ends of the strip, there is no preventive force to stop center buckle. A further reason is that there was less contact area due to the increase in work rolls cross angle $\left(1^{\circ}\right)$.

3.6. Strip Shape and Profile during 2nd Pass under Various WRC Angles and WRS Values. Figure 13(a) shows the effect of work rolls cross angle on the exit strip profile after the 2 nd pass with no work roll shifting, $20 \mathrm{rpm}$ speed, and $80 \mathrm{~mm}$ strip width at 1.3 speed ratio under lubricated conditions. The results were similar to those observed during the 1st pass (Figure 4(a)). At zero work rolls cross angle, the strip profile tends to decrease significantly towards the edges resulting in strip crown. However, when the work rolls cross angle changes from 0 to $1^{\circ}$, the exit strip profile tends to become flat leading to a larger efficiency of the shape and profile control as observed during the 1st pass.

Figure 13(b) shows the effect of work roll shifting ( 0 and $8 \mathrm{~mm}$ ) on strip profile after the 2 nd pass without work rolls cross angle, $20 \mathrm{rpm}$ speed, and $80 \mathrm{~mm}$ strip width at 1.3 speed ratio under lubrication conditions. Similar to the 1st pass (Figure 5(a)), work roll shifting is not significant in reducing the strip profile compared to work rolls cross angle effect; however, with an increase of work roll shifting value, the strip profile becomes better.

3.7. Strip Profile and Shape during 3rd Pass under Various WRC Angles and WRS Values. Figure 14(a) shows the effect of work rolls cross angle on the exit strip profile after the 3rd pass with no work roll shifting, $20 \mathrm{rpm}$ speed, and $80 \mathrm{~mm}$ strip width at 1.3 speed ratio under lubricated conditions. The results were similar to those observed during 1st and 2nd passes, showing a significant improvement in strip profile with an increase in work rolls cross angle from $0^{\circ}$ to $1^{\circ}$. The exit strip profile tends to become flat leading to a larger efficiency of the shape and profile control as observed during the 1 st and 2 nd passes.

Figure 14(b) shows the effect of work roll shifting (0 and $8 \mathrm{~mm}$ ) on strip profile after the $3 \mathrm{rd}$ pass without work roll cross angle, $20 \mathrm{rpm}$ speed, and $80 \mathrm{~mm}$ strip width at 1.3 speed ratio under lubrication conditions. Similar to the 1st and 2 nd passes, work roll shifting is not significant in reducing the strip profile as well as thickness compared to work rolls cross angle effect.

3.8. Improving the Strip Profile Using Speed Ratio. Figures 15(a) and 15(b) show the effect of speed ratios (1.1 versus 1.3) at work rolls cross angles $0^{\circ}$ and $1^{\circ}$ with no work roll shifting, $20 \%$ reduction, and $20 \mathrm{rpm}$ rolling speed for $80 \mathrm{~mm}$ strip width under lubricated conditions. At $0^{\circ}$ cross angle, there is essentially no significant improvement in strip profile or thickness distribution with an increase in speed ratio. Even at higher work rolls cross angle of $1^{\circ}$, there is no significant improvement in strip profile; however, a lower speed ratio results in a better reduction in strip thickness.

3.9. Improving the Strip Profile Using Lubrication. Figure 16 shows a comparison of rolling condition (dry and lubricated) at speed ratio 1.3 and work rolls cross angles $0^{\circ}$ and $1^{\circ}$ with no work roll shifting and $20 \mathrm{rpm}$ rolling speed for $80 \mathrm{~mm}$ strip width. Under dry conditions, the strip profile improved with an increase in work rolls cross angle from $0^{\circ}$ to $1^{\circ}$, however, with no reduction in thickness. Under lubricated conditions, there was significant improvement in strip profile with an increase in work rolls cross angle, however, associated with an increased thickness. 


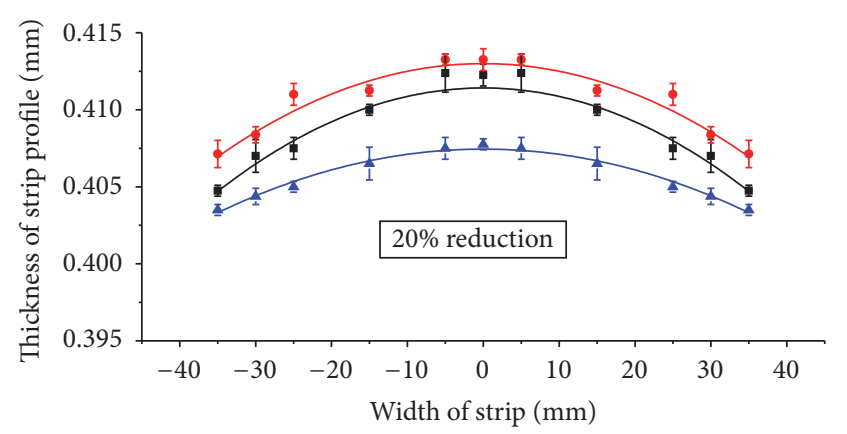

- = "0 $0^{\circ}$ WRC, 1 st Pass"

- = "0.5 WRC, 1st Pass"

$\Delta=$ " $1{ }^{\circ}$ WRC, 1 st Pass"

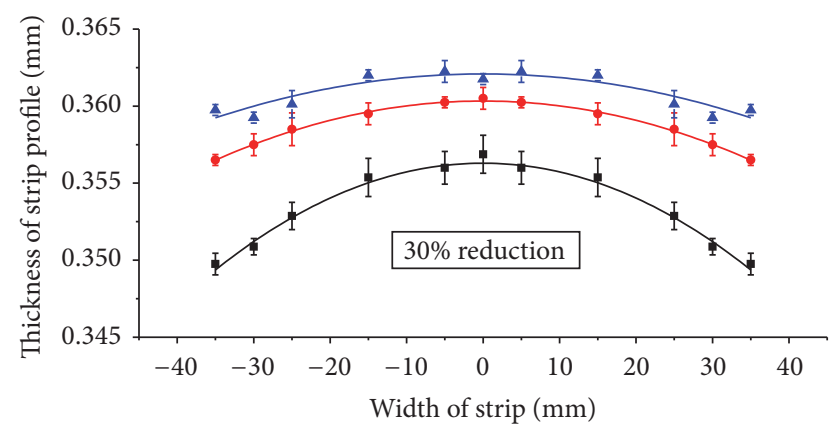

- = "0 ${ }^{\circ} \mathrm{WRC}, 1$ st Pass"

- = "0.5 WRC, 1st Pass"

$\Delta=$ " $1{ }^{\circ}$ WRC, 1 st Pass"

FIGURE 9: Strip profile at (a) 20\% reduction and (b) 30\% reduction.

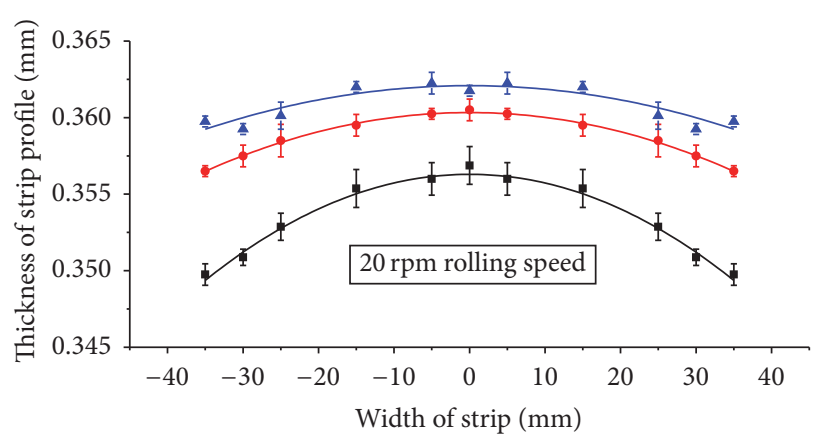

- = "0 ${ }^{\circ}$ WRC, 1 st Pass"

- = “0.5 WRC, 1st Pass"

॥ = " $1{ }^{\circ}$ WRC, 1 st Pass"

(a)

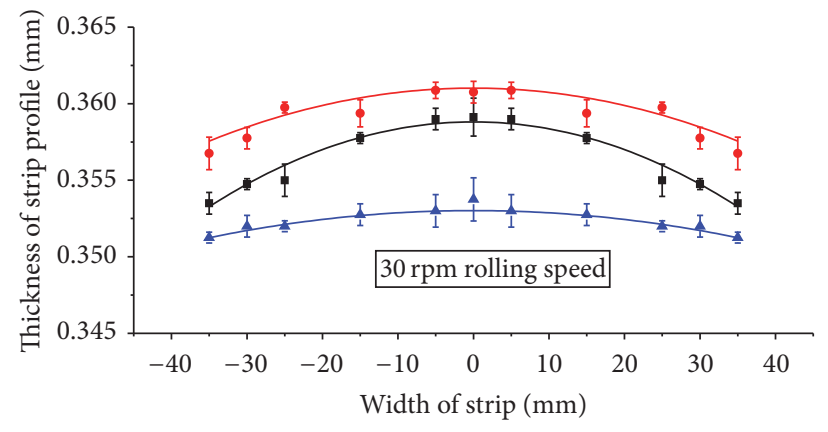

- = "0 ${ }^{\circ}$ WRC, 1 st Pass"

- = "0.5 WRC, 1st Pass"

॥ = "1 ${ }^{\circ}$ WRC, 1 st Pass"

(b)

FIGURE 10: Strip profile at various cross angles for (a) $20 \mathrm{rpm}$ rolling speed and (b) $30 \mathrm{rpm}$ rolling speed.

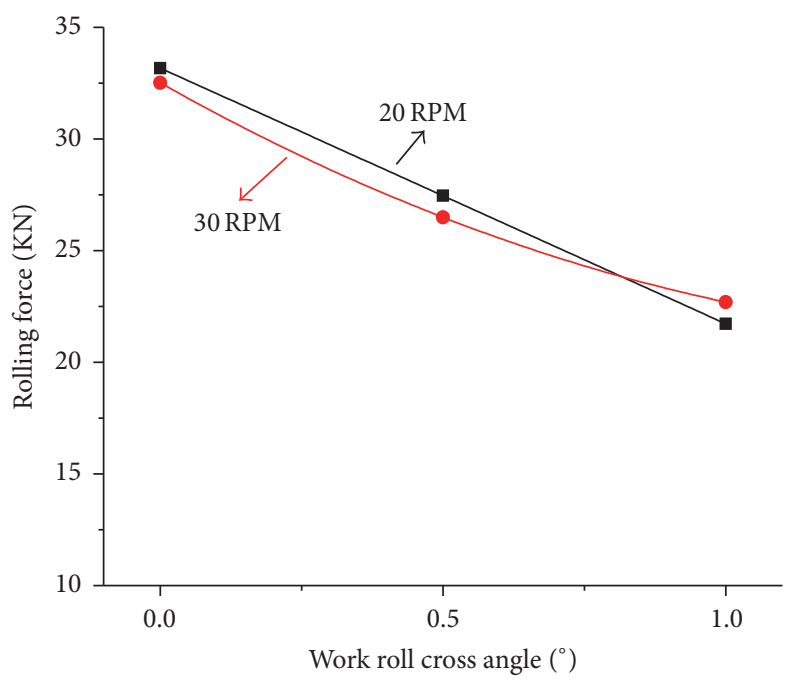

FIGURE 11: Effect of rolling speed on rolling force. 


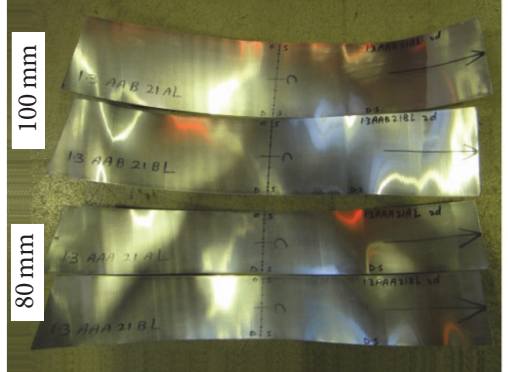

Angle $0^{\circ}$

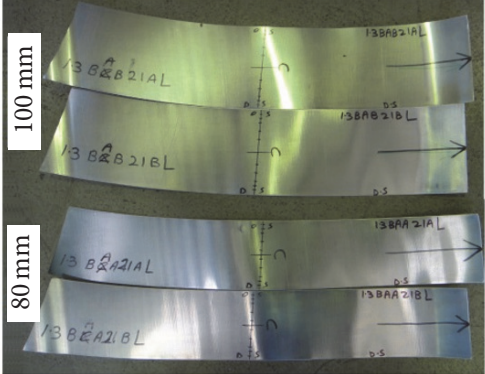

Angle $0.5^{\circ}$

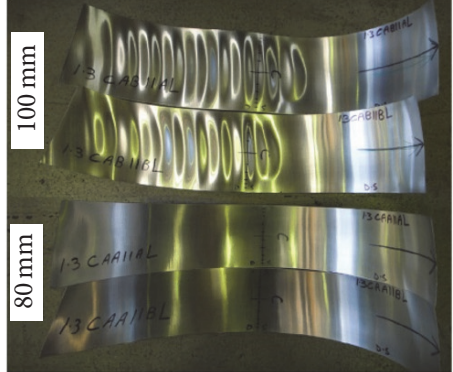

Angle $1^{\circ}$

FIGURE 12: Strip shapes after rolling at various work roll cross angles.

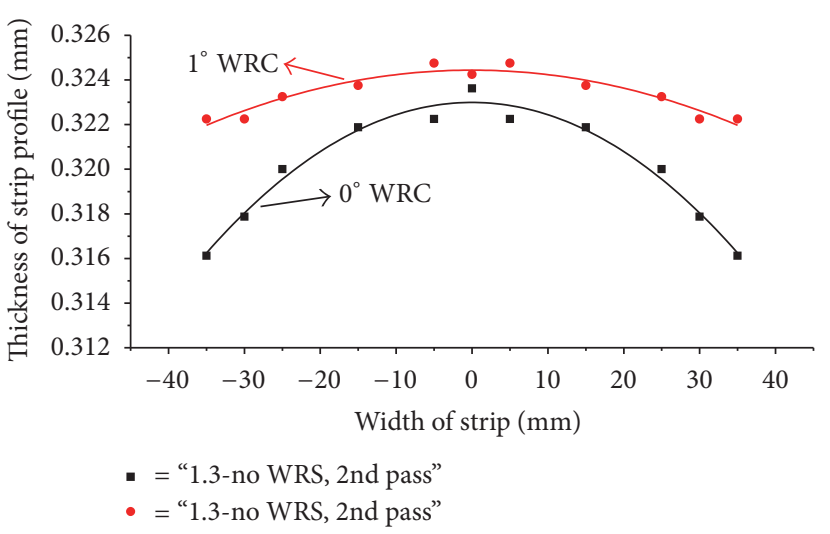

(a)

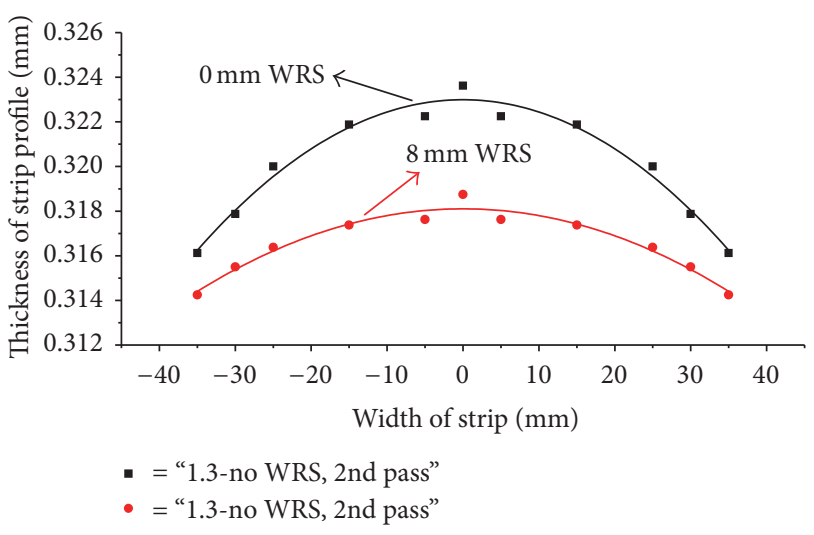

(b)

FIGURE 13: (a) Effect of work rolls cross angle on strip profile. (b) Effect of work roll shifting on strip profile, 2nd pass.

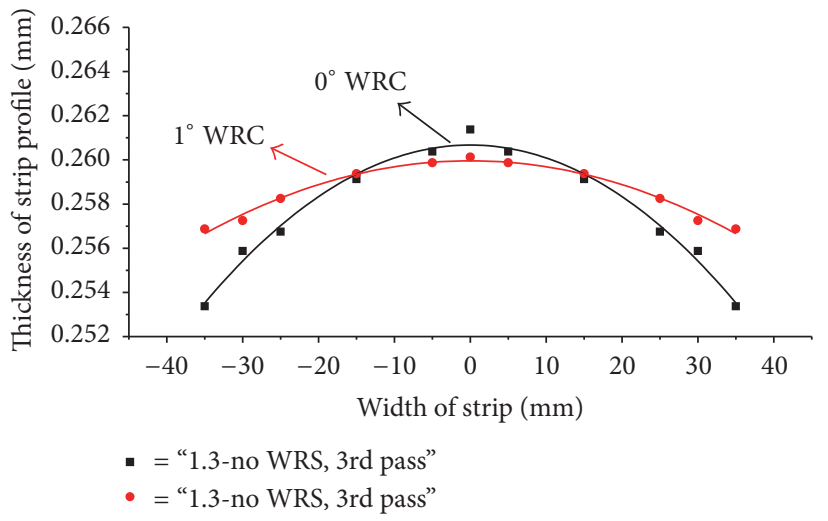

(a)

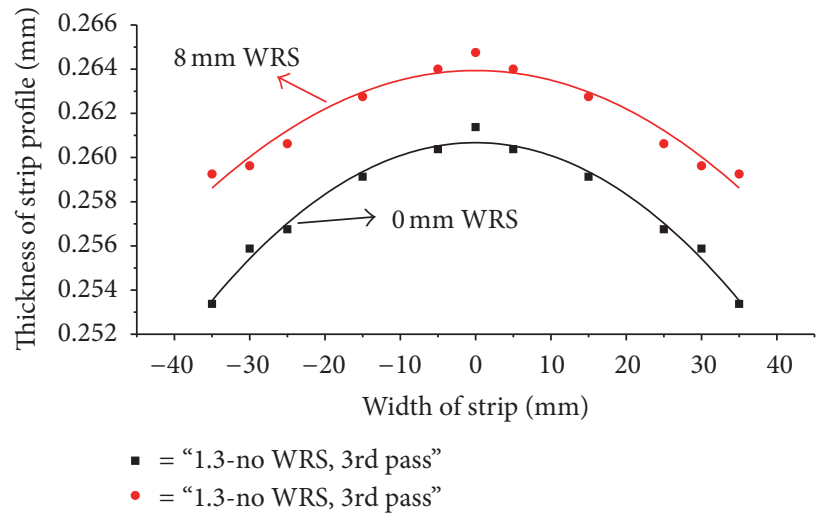

(b)

FIGURE 14: (a) Effect of work rolls cross angle on strip profile. (b) Effect of work roll shifting on strip profile, 3rd pass.

\section{Conclusions}

The exit strip profile for thin strip in cold rolling of aluminum was studied. The effects of work roll cross angle, work roll shifting, reduction ratio, and rolling speed were investigated. The following conclusions can be drawn:

(i) Significant improvement was observed with an increase of WRC angle and WRS value which resulted in a better strip profile, reduced strip thickness, and a drop of rolling force. Higher WRS combined with higher WRC angle ensures minimum resistance to the transverse flow of material, while uniform distribution of rolling pressures on the strip results in a significant reduction of strip profile as well as rolling force.

(ii) Higher reduction ratio ensures a better exit strip shape which is attributed to uniform distribution of rolling forces in the roll gap. Also, the strip profile 


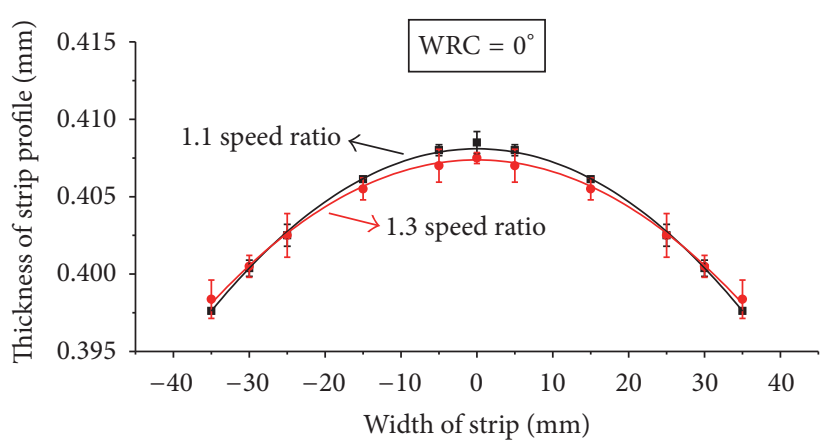

(a)

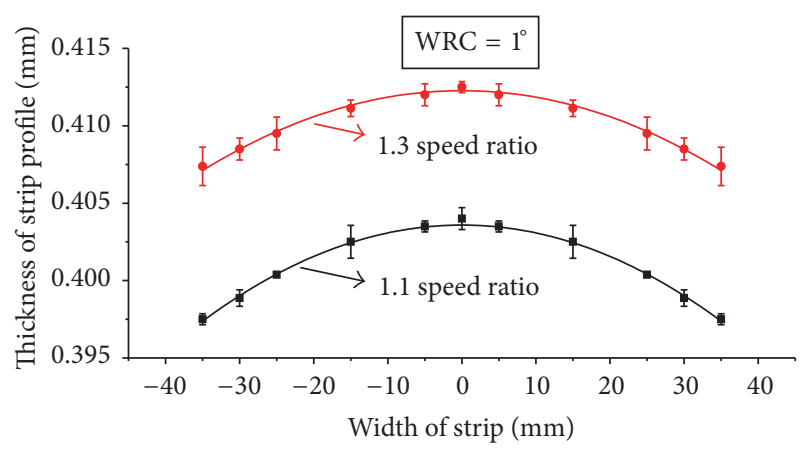

(b)

FIGURE 15: The effect of WRC on strip profile for different speed ratios, (a) angle $0^{\circ}$, and (b) angle $1^{\circ}$, 1st pass.

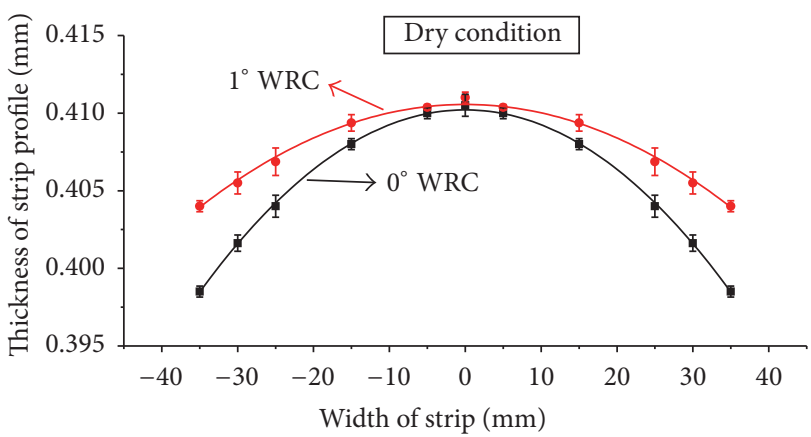

(a)

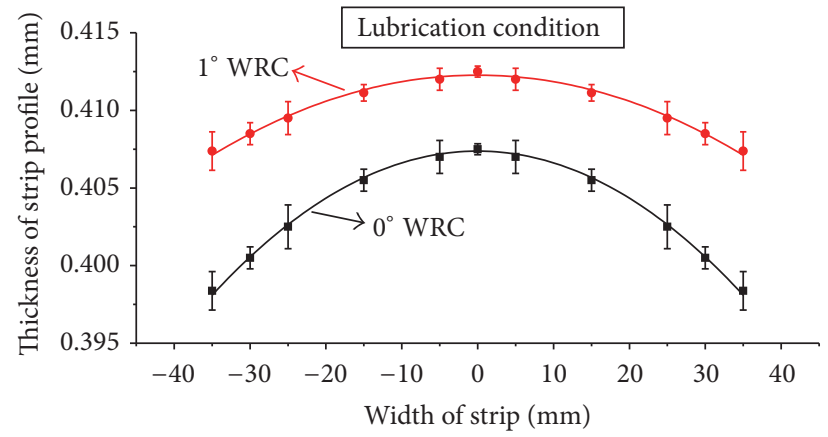

(b)

FIGURE 16: The effect of WRC on strip profile under (a) dry condition and (b) lubricated condition, 1st pass.

tends to become better with a smaller strip width, which helps to reduce rolling force. However, increasing the rolling speed does not significantly reduce the rolling force but results in better strip profile, which again is improved with an increase of WRC angle.

(iii) The effect of rolling parameters was similar during 1st, $2 \mathrm{nd}$, and $3 \mathrm{rd}$ passes, although it is implied that the strip thickness is consequently reduced during multiple passes.

(iv) The effect of speed ratio is only enhanced at an optimum at higher work rolls cross angle.

(v) Strip profile is significantly improved under lubricated conditions compared to dry rolling under the same operating conditions.

\section{Competing Interests}

The authors declare that they have no competing interests.

\section{Acknowledgments}

This work was supported by Australian Research Council (ARC), which was significantly appreciated.

\section{References}

[1] Z. Y. Jiang, D. Wei, and A. K. Tieu, "Analysis of cold rolling of ultra thin strip," Journal of Materials Processing Technology, vol. 209, no. 9, pp. 4584-4589, 2009.

[2] Z. Y. Jiang, H. T. Zhu, A. K. Tieu, and W. H. Sun, "Modelling of work roll edge contact in thin strip rolling," Journal of Materials Processing Technology, vol. 155-156, pp. 1280-1285, 2004.

[3] Z. Y. Jiang, A. K. Tieu, X. M. Zhang, C. Lu, and W. H. Sun, "Finite element simulation of cold rolling of thin strip," Journal of Materials Processing Technology, vol. 140, no. 1-3, pp. 542-547, 2003.

[4] W. L. Roberts and W. Roberts, Cold Rolling of Steel, Marcel Dekker, New York, NY, USA, 1978.

[5] D. Rawsthorne, Mechanics of Thin Strip Rolling, Universit of Wollongong, 2007.

[6] Z. Y. Jiang, H. T. Zhu, A. K. Tieu, and W. H. Sun, "Modelling of work roll edge contact in thin strip," Journal of Materials Processing Technology, vol. 155-156, pp. 1280-1285, 2004.

[7] P. Montmitonnet, E. Massoni, M. Vacance et al., "Modeling for geometrical control in cold and hot rolling," Ironmaking and Steelmaking, vol. 20, no. 4, pp. 254-260, 1993.

[8] Z. Y. Jiang, H. T. Zhu, D. B. Wei, and A. K. Tieu, "An approach to analyse the special rolling of thin strip," Journal of Materials Processing Technology, vol. 177, no. 1-3, pp. 130-133, 2006.

[9] R. M. Guo, "Optimal profile and shape control of flat sheet metal using multiple control devices," IEEE Transactions on Industry Applications, vol. 32, no. 2, pp. 449-457, 1994. 
[10] V. B. Ginzburg, "Roll crossing and shifting system," Google Patents, 1997.

[11] N. Kiyoshi, H. Y. O. Shigeru, M. Yasushi, and K. Akihiko, "High reduction rolling technology on pair cross mill," Nippon Steel Technology Report no. 75, 1997.

[12] V. B. Ginzburg and R. Ballas, Flat Rolling Fundamentals, CRC Press, 2000.

[13] J. S. Wang, Z. Y. Jiang, A. K. Tieu, X. H. Liu, and G. D. Wang, "Analysis of thrust force in a work roll shifting mill," International Journal of Mechanical Sciences, vol. 48, no. 10, pp. 10951102, 2006.

[14] K. Kitamura, I. Yarita, N. Suganuma, T. Nakanishi, and K. Toyoshima, "Edge-drop control of hot and cold rolled strips by a tapered-crown work roll shifting mill," Iron and Steel Engineer, no. 2, pp. 27-32, 1995.

[15] T. Hiruta, I. Akagi, and N. Mizushima, "Development of advanced transverse thickness profile control of thin hard steel strips at tandem cold rolling mill," Kawasaki Steel Technical Report, vol. 37, pp. 19-24, 1997.

[16] R.-M. Guo, "Characteristics of rolling mills with roll shifting," Iron and Steel Engineer, vol. 65, no. 12, pp. 45-54, 1988.

[17] T. Nakanishi, T. Sugiyama, Y. Iida, and T. Hashimoto, "Application of work roll shift mill (HCW-mill) to hot strip and plate. Hitachi review," Hitachi Review, vol. 34, no. 4, pp. 153-160, 1985.

[18] V. B. Ginzburg, High-Quality Steel Rolling: Theory and Practice, CRC Press, 1993.

[19] M. Salimi and F. Sassani, "Modified slab analysis of asymmetrical plate rolling," International Journal of Mechanical Sciences, vol. 44, no. 9, pp. 1999-2023, 2002.

[20] A. Aljabri, Z. Y. Jiang, and D. B. Wei, "Analysis of thin strip profile during asymmetrical cold rolling with roll crossing and shifting mill," Advanced Materials Research, vol. 894, pp. 212216, 2014.

[21] Z. Jiang, X. Du, Y. Du, D. Wei, and M. Hay, "Strip shape analysis of asymmetrical cold rolling of thin strip," Advanced Materials Research, vol. 97-101, pp. 81-84, 2010.

[22] D. Pan and D. H. Sansome, "An experimental study of the effect of roll-speed mismatch on the rolling load during the cold rolling of thin strip," Journal of Mechanical Working Technology, vol. 6, no. 4, pp. 361-377, 1982. 

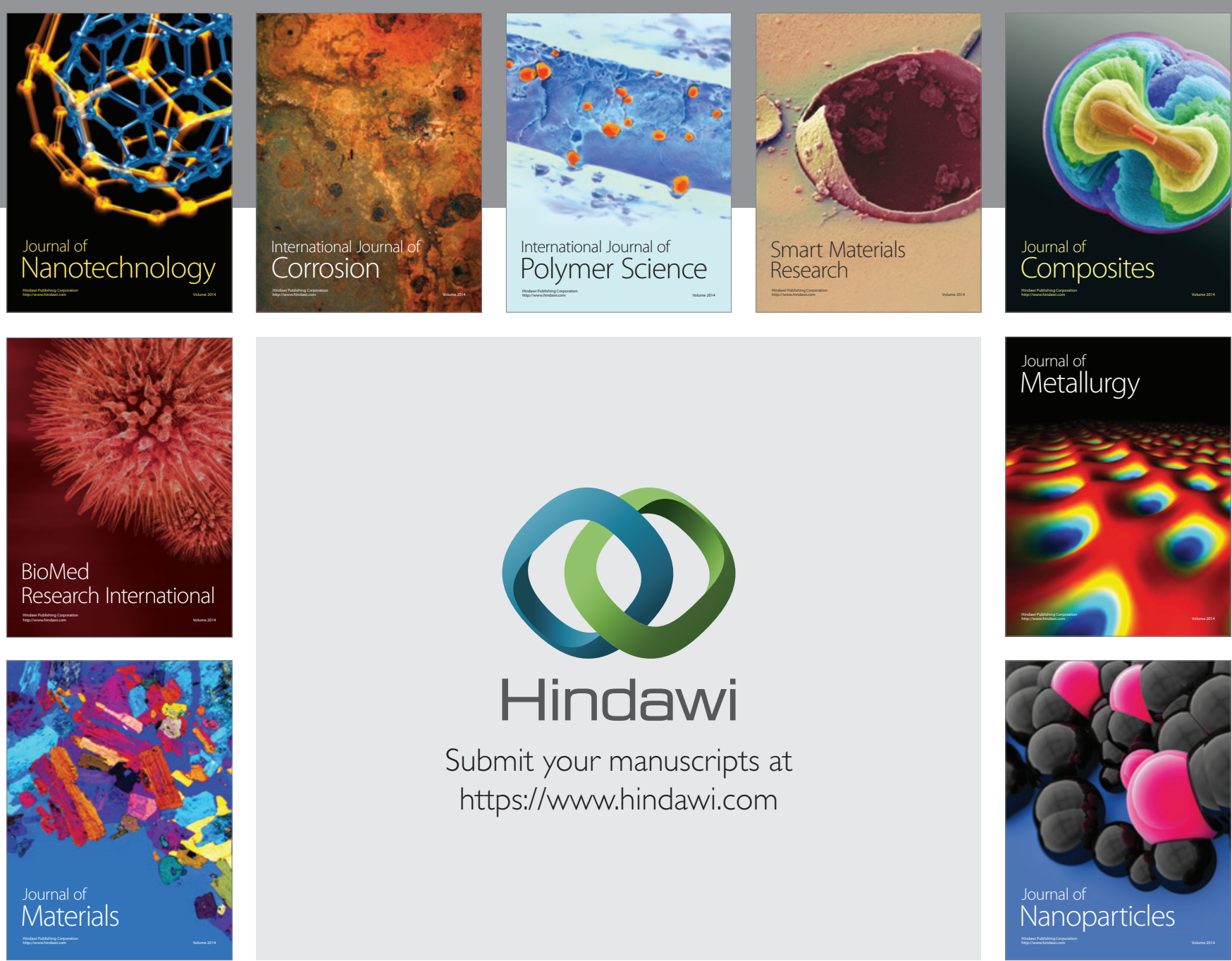

\section{Hindawi}

Submit your manuscripts at

https://www.hindawi.com

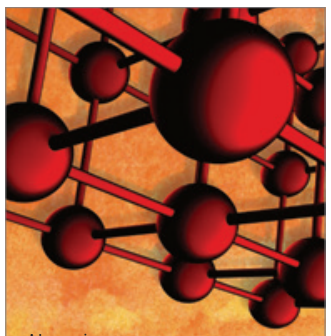

Materials Science and Engineering
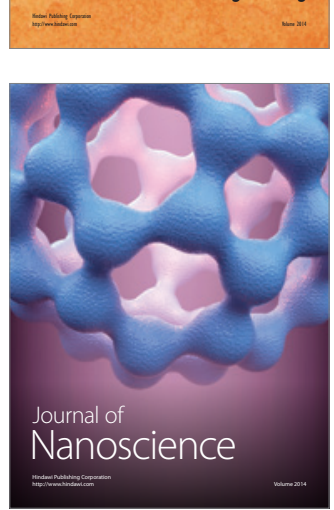
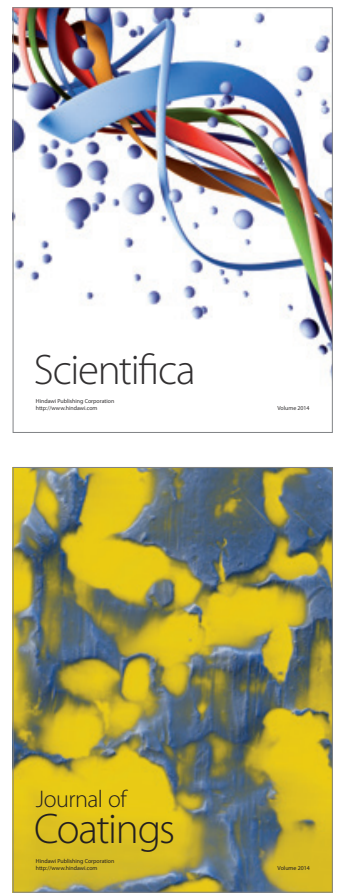
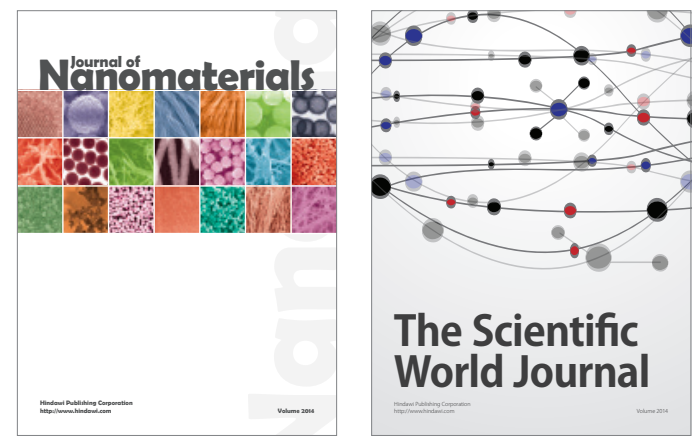

The Scientific World Journal
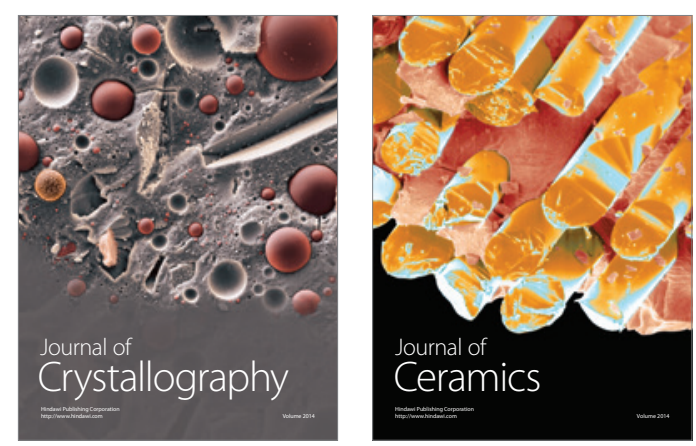
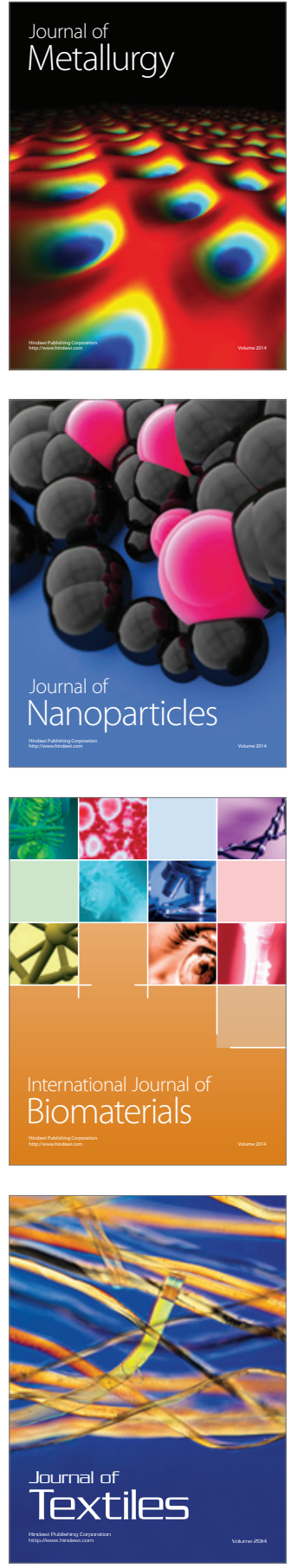